\title{
Using Weblog in Learning English and Encouraging Adaptation among International Students in Perlis
}

\author{
Ina Suryani \& Shafiq Hizwari \\ Center of Communication Technology and Human Development \\ Universiti Malaysia Perlis, Malaysia \\ E-mail: inasuryani@unimap.edu.my \\ Md. Aminul Islam \& Hazry Desa \\ School of Business Innovation and Technopreneurship \\ Universiti Malaysia Perlis, Malaysia
}

Received: October 17, 2011 Accepted: Novemer 10, 2011 Published: March 1, 2012

doi:10.5539/hes.v2n1p27

URL: http://dx.doi.org/10.5539/hes.v2n1p27

\begin{abstract}
This study looks at the correlation of the English learning which is by using weblog and the adaptation for international students at Universiti Malaysia Perlis. The study was conducted on the first batch of International students. There were 37 students from three countries with the majority from China followed by Indonesia and Sudan. The students were in the Intensive English Course for nine months which was a pre-requisite before entering into the first year of Bachelor Degree program. The adaptation level is determined using the Sociocultural Adaptation Scale (SCAS) by Searle and Ward (1990). The English proficiency level is determined by using DYNED software. This courseware is designed to help learners acquire the target language in a natural but accelerated mode of learning. The result of the study shows that the students have improved their language competencies after attending the course. Although the language improvements differ individually based on their postings in the blog most of the students show better flow of writing and seemed to be at ease as compared to earlier stages of the course.
\end{abstract}

Keywords: Weblog, Adaptation, International students

\section{Introduction}

Weblog is gradually becoming the new popular culture and to some extent has taken the place of journal entries as the medium of expression. In teaching and learning, weblog has also been used as a tool as students can use it as a personal space to read and write as well as use it as use it for communal purpose. On the other hand, proficiency in the language alone is not a guarantee for successful communication among Non-Native Speakers. Therefore as a part of the language course design, Universiti Malaysia Perlis has taken the stride to enhance its preparatory Intensive English Course by integrating elements of intercultural communicative competence. In view that the IEC course is offered to the international students who have just arrived to the host country, the elements of intercultural communicative competence through weblog and adaptation have been put in focused.

According to Johnson (2004) blog could be perceived as electric journal in which allowing the user to keep their writings. In the advent of CMC and technology based learning, there has been a massive increase in the usage of blog as the medium of writing. Johnson (2004) has quoted example on the Bay Area Writing Project which organized the Educational Blogger Network (edBlogNet) with the purpose of helping kindergarten through university teachers "use web log technology for the teaching of writing and reading across the disciplines and it proves to be a success in the United States. In our very own ground there were various attempts in the local tertiary education with universities such as IIUM, UniMAP and USIM having blog writing courses with the aim of improving the writing capacity of students (Shafiq and Ina, 2011)

While language proficiency is a desired skill in the advancement of students academic, the other factors related to real life situation also play important role in the students' academic as most educators have been acquainted with the Maslow's hierarchy of needs. In short while mastery of English language is expected to help the international 
students do well academically, proficiency in the language is also hoped to help the students adapt in the new environment better.

Berry and Kim (in Handojo, 2000) have listed out the dimension of changes need to be faced in adaptation which are namely physical, biological, social, cultural and psychological. The list of challenges requires adjustment to the new weather and climate, different foods, diets and diseases. Social support and friendship may be cut off upon being uprooted from the indigenous environment. The new surroundings may even demand a change in attitudes and values. For the international students, the adaptation extends to other changes in dimensions (Ina, Huzili, and Kuldip, 2008)

- Academic; system, reference used, evaluation method

- Teaching and learning style; supervision cues, peers, teachers and lecturers

- Language; variety used, formal and informal language

- Financial; fees, currency, banking system, billing system, logistic cost, unfamiliar services

Failure to adapt to the new changes upon migration would collapse the students' daily performance and functioning and could lead to negative outcomes in the students' health, psychological wellbeing and academic performance in the long run (Poyrazli, Kavanaugh and Baker, 2001). It is believed that the faster the international students adapt to the new culture, the better they will do academically (Gholamrezaei, 1996). As educators, efforts must be made to assist the students' adaption and learning progress and thus brings on the departure points for this study.

This paper is aimed to illustrate the use of weblog in learning English in the easing adaptation, determine if the international students improved their English after undergoing the Intensive English Program, and identify the correlation between English language proficiency and adaptation

\section{Methodology}

The students entered the Intensive English Course (IEC) for six months before enrolling into the undergraduate programs. The weblog was created during class in the language lab using the Blogspot.com and was in effect throughout the semester.

\subsection{Inventing the Blog}

The instructor created a class weblog and posted some topics to trigger ideas. The students and the other instructors also created their weblog and began posting some topics and pictures. Next, the instructor created the URL link list of all the students and instructors in the class weblog, making it easier to communicate and view each other's posting. The Students login to the site http://eicclass.blogspot.com and their own weblog for the duration of the semester to publish their entries.

\subsection{The Weblog Layout}

The weblog comprises of two columns. One column is reserved as the space to write the entries and the recent date and time of the entry. Underneath of the writing space is the comment area where the readers can post comments on the issue. Blogspot.com also allows function for trackbacks and this gives a sense of virtual conversation.

In the right column, there is a list of blog belonging to the students and the language instructors. This column also consist of the University logo, pictures of the language instructors, the blog archives, the URL links for English learning website and reading materials. More functions were added later such as the Word-Match-Up game and the Join In' button for weblog followers. The layout of the blog is as shown below (Figure 1)

\subsection{The Lessons}

The students add their preferred weblog link on their own site. The instructor posts topics regularly on the class weblog to trigger discussion and more ideas. The students are also encouraged to write on the activities that they took part in such as the class trip to the theme park, the snake farm and the University functions and events. The class time allocated for weblog writing is one hour and a half lesson, twice a week. They are also encouraged to visit their friends' weblog and give comment.

One of the sessions is meant for individual blog whereas the other is meant for discussion or class blogging in which all students must respond to the topic posted by the instructor on the class blog. This particular exercise requires the students to give respond by posting their thoughts on the comment section of blog. These comments must however be done during class time and they were given ample time to answer. At times, the instructor would prepare an extended activity or post a link to websites that offers further explanation or more exercises related to the topic of the day. Once everybody in the class has responded the instructor would then discuss with the students all of the individual comments and give the answers. This is when the instructor focuses on shedding the lights on matters 
concerning intercultural boundaries in language. The instructors were to avoid from giving judgmental comments and too much emphasis on the grammatical structure. The emphasis would be more on the aesthetic value, their ideas and content.

\subsection{The Adaptation Scale}

The adaptation scale used as instrument for the study is inspired by Sociocultural Adaptation Scale (SCAS) by Searle and Ward (1990) which has been tested and applied in his studies on international students in other countries like Singapore, New Zealand and Australia (Ward\& Kennedy; 1993). The items from the instrument are used in this study as an adaptation scale for UniMAP context.

The English Proficiency is measured using the DynED Courseware, the Placement Test. The test was given at the beginning and at the end of the IEC program. The proficiency test covers the main four aspects of language skills which are Listening, Speaking, Reading and Writing.

\section{Findings}

The weblog is found to be useful for the students to express their ideas and thoughts at ease and lighten up the discussion. The topics are related to real life situation and this brings forth many issues on adapting to the new environment. Some of the weblog entries show reflections on their new environment such as their new past time, the food and interesting places that they discover.

Some of the challenges faced are accessing the site from outside the language lab. The students could not perform the task in their hostel due to lack of facility. They have just arrived to study in Perlis and many of them do not have their own personal computer. However the university provides many computers in the library and they can use the computer in the language lab throughout the day. Having the two sessions a week gives the instructor and the students' ample time to work on the weblogs.

Another problem is the failure to read and comment on their friend's weblog. The students are informed that the instructor keep tab on the comment and allocate marks for this and the comments start coming in. As the lessons move on, the students are more aware of the task and began to plan on what to write by taking pictures.

Data analysis done using SCAS indicated to be internally consistent with Cronbach Alpha of 0.914.). This finding confirms that SCAS is internally reliable, just like the studies conducted by the other studies (Ward \& Kennedy, 1993a, 1993b, 1993c; Ward 1996, Searle and Ward, 1990, Ward \& Bosner, 2001)

There was a significant correlation between the scores of test one and test two at $1 \%$ significance level. It was found that there was a significant increment in the English language scores at the end of the course as compared to the scores taken at the beginning of the course. The finding supports that the students have significantly improved their English language proficiency towards the end of the program, based on the scores of DYNED tests given.

It was found that there was no statistical significance between test one and overall adaptation score. Even though there was no statistical significance, Test One was found to be negatively correlated with the overall adaptation score. This means that at the point of arrival and entry into the program, good scores in English language proficiency test does not indicate better adaptation. (Ina \& Islam, 2011)

The correlation between adaptation score with Test two was also not significant at 5\% significance level. Even though the value is not statistically significant; the fact that the correlation between test two and adaptation score was found to be positive. Therefore it can be inferred that those who improved their English also have improved in their adaptation score. The correlation between adaptation score with Test two was also not significant at $5 \%$ significance level. Even though the value is not statistically significant; the correlation between test two and adaptation score was found to be positive. Therefore it can be inferred that those who improved their English also have improved in their adaptation score (Ina \& Islam M.A., 2011).

\section{Discussion}

The result of the study shows that the students have improved their language competencies after attending the course. Although the language improvements differ individually based on their postings in the blog most of the students show better flow of writing and seemed to be at ease as compared to earlier stages of the course. The students have also demonstrated their understanding that communication transcends beyond the language itself and thus supports the finding that it helps them in adapting to the host culture. Adaptation is inevitable for the students to function normally. The demand to learn a wide range of culturally defined and unfamiliar roles under pressure of time and expectations poses stress. Adaptation failure would collapse the students' daily performance and functioning which could lead to negative outcomes in health and academic performance in the long run. 


\section{Acknowledgement}

This paper is a part of a bigger study funded by Fundamental Research Grant by Ministry of Higher Education, Malaysia (MoHE). The research team expresses gratitude and thanks to UniMAP and MoHE for the fund that has made the study possible. Credits also go to those who have contributed positive development of the research.

\section{References}

Alptekin, C. (2002). Towards intercultural communicative competence. ELT Journal, 56(1), 57-63. http://dx.doi.org/10.1093/elt/56.1.57

Berry, J.W., \& Kim, U. (1988). Acculturation and mental heath. In P. Dasen, J.W. Berry, \& N. Sartorius (Eds.), Health and cross-cultural psychology. London: Saga. pp. 207-236

Byram, M., Gribkova, B., \& H. Starkey. (2002). Developing the intercultural dimension in language teaching: A practical introduction for teachers. Stasbourg: Council of Europe

Handojo, V. (2000). Attachment Styles, Acculturative Attitudes/Behaviors and Stress among Chinese Indonesian Immigrants in the United States of America. Doctoral dissertation. Fuller Theological Seminary.

Ina Suryani, \& Islam M. A. (2011). A study on Correlation between English Proficiency and Adptation among International Students in Engineering Focused University in proceeding for The 1st International Malaysia-Ireland Join Symposium on Engineering Science and Business. 8-10 June 2011.

Ina, S., Huzili, H., \& Kuldip.K. (2008). Utilizing the Findings of International Adaptation Research in the Counselling of Malaysian Students in Japan, Journal of Human Capital Development.

Ina.S, D.Hazry, \& Intan, M. (2008). Designing Acculturation Scale for Malaysian Students in Japan Universities, The Journal of INTI International Education Group, INTI Pub. House, Special Issue on Teaching and Learning, pp. 105-109

Maruyama, M. (1998). Cross-Cultural Adaptation and Host Environment: A Study of International Students in Japan. Doctoral Dissertation, University of Oklahoma.

Poyrazli. S, Kavanaugh P. K., \& Baker, A. (2001) Adjustment Issues of Turkish College Students Studying in the United States. College Student Journal, 7(1), 73-83

Searle, W., \& Ward, C. (1990). The prediction of psychological and socio-cultural adjustment during cross-cultural transitions. International Journal of Intercultural Relations, 14, 449-464. http://dx.doi.org/10.1016/0147-1767(90)90030-Z

Shafiq Hizwari Md. Hashim \& Ina Suryani Ab. Rahim. (2011). Enhancing the Adaptation Process for International Students in Perlis through English Blog Learning in proceeding for 20th (Malaysian English Language Teachers Association) MELTA International Conference 2011, 30-1 June 2011.

This paper is a part of a bigger study funded by Fundamental Research Grant by Ministry of Higher Education, Malaysia (MoHE). The research team expresses gratitude and thanks to UniMAP and MoHE for the fund that has made the study possible. Credits also go to those who have contributed positive development of the research.

Ward, C., \& Boshner, S. (2001). The A, B, Cs of Acculturation: Theory Research and Applications. International Congress of Applied Psychology. N.Zealand

Ward, C., \& Kennedy, A. (1993a). Acculturation and cross-cultural adaptation of British residents in Hong Kong. Journal of Social Psychology, 133, 395-397. http://dx.doi.org/10.1080/00224545.1993.9712158

Ward, C., \& Kennedy, A. (1993b). Psychological and sociocultural adjustment during crosscultural transitions: A comparison of secondary students overseas and at home. International Journal of Psychology, 28, 129-147. http://dx.doi.org/10.1080/00207599308247181

Ward, C., \& Kennedy, A. (1993c). Where's the culture in cross-cultural transition? Comparative studies of Sojourner Adjustment. Journal of Cross-Cultural Psychology, 24, 221-249. http://dx.doi.org/10.1177/0022022193242006 


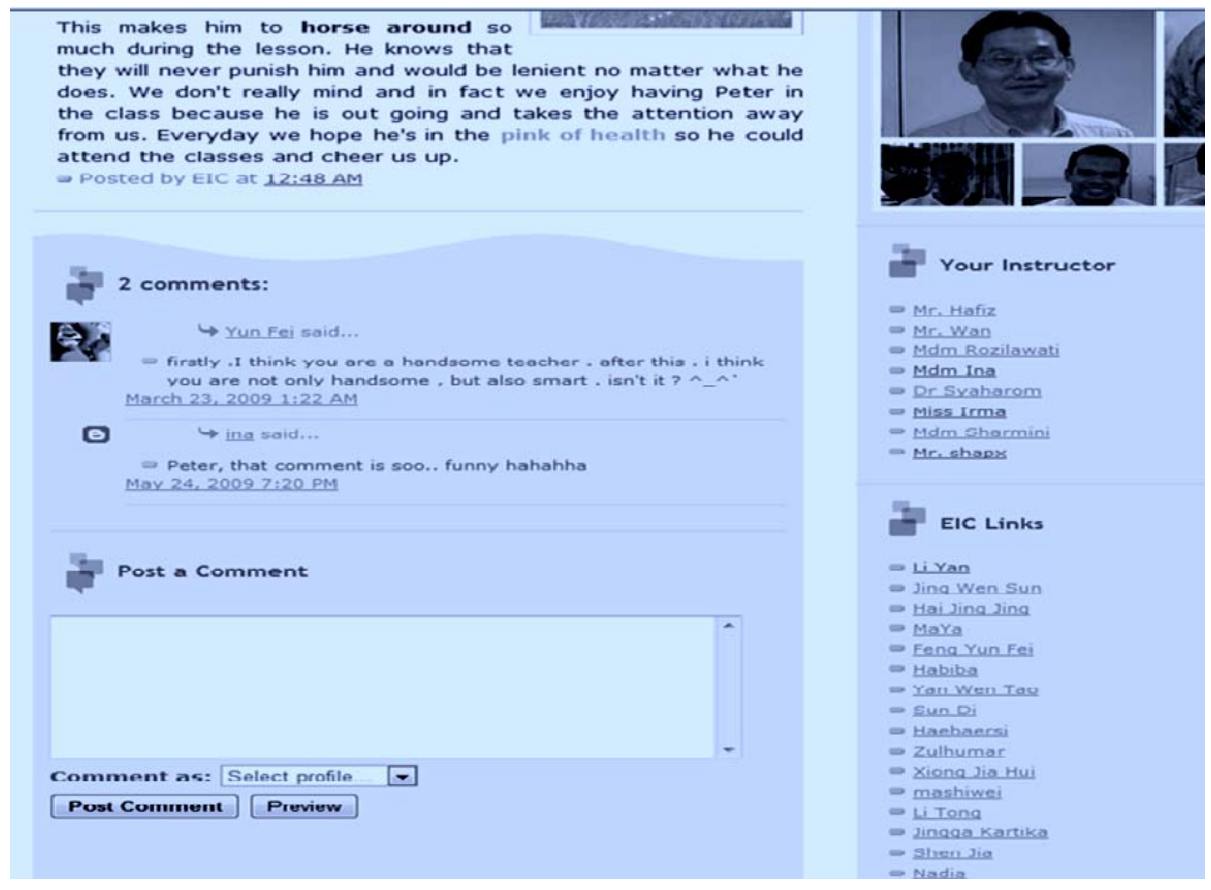

Figure 1. The class weblog

What I Bought .

Actually I don't go to huge shopping mall very often, but it's necessary for me to do some shopping everyday for my daily life.I need something like food,drinks, washing stuffs, clothing and so on.Let's go and check what I got last week.

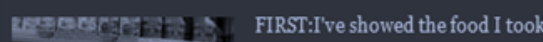

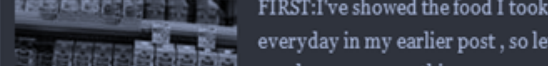
7iching

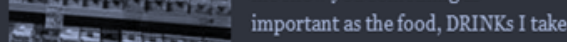

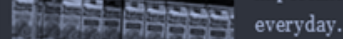
I love orange juice very much and I take it almost everyday, so of course it's the most important thing need to buy.Sometimes I order this drink when I take my lunch in the restaurant, and sometimes I would buy it in supermarket and bring it back home .I love enjoying my nice orange juice when I'm doing something just like watching movies or talking with my pals.It gives me

enough Vc and keeps my day being brightly.I love orange juice...

Of course sometimes I would take applejuice or strawberry instead.

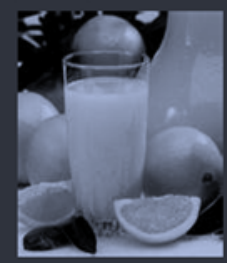

SECOND:

You have to admit that life here is more than bored. We are still too young to take the quiet life like this.So we tried our best to find something interesting.just like mouses are trying to find some more rice..lol.

\section{Zulihuma}

Halo everyone, my name is Zulihuma(Zulhumar), but you can call me Zul or Zuli, i got it in class, because it is so easy to call. That is why !!! I am 20 years old. Sometimes i like to keep quiet. I like to listen to music and play some balls, especially basketball and Ping-Pong. You know, i also a good player.Do not think of me who is not tall. hEe... okay, i just introduced here.

a Posted by EIC at 5:00 AM
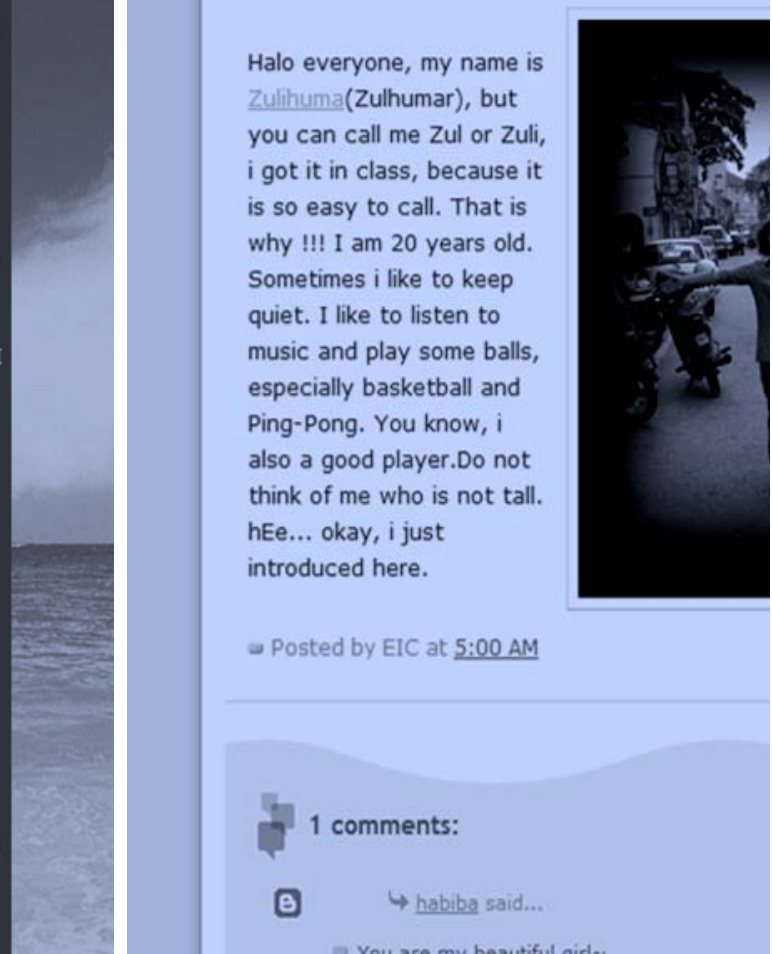

1 comments:

(E) 4 habiba said... - You are mv beautiful airl

Figure 2. Sample of students' weblog 